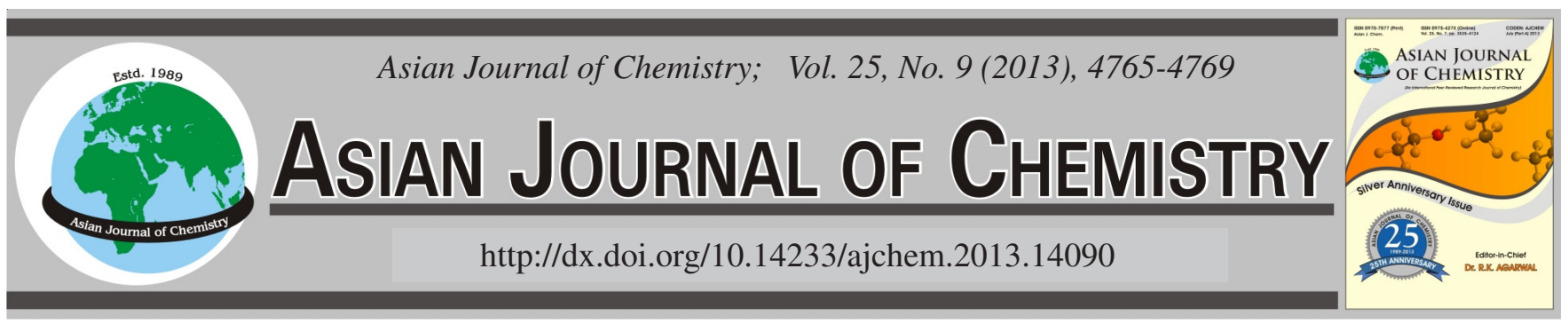

\title{
Energy-Volume Coefficient and Limiting Excess Molar Volume Studies of Some Carbohydrates in Dilute Aqueous Solutions at 288.15 K
}

\author{
Sudhakar S. Dhondge ${ }^{1, *}$, Alka Dhondge $^{2}$, Kesharsingh J. Patil $^{3}$ and Preeti A. Tomar ${ }^{4}$
}

${ }^{1}$ Post Graudate Department of Chemistry, S.K. Porwal College, Kamptee-441 002, Nagpur, India

${ }^{2}$ Department of Biochemistry, L.A.D. and Smt. R.P. College, 440 010, Nagpur, India

${ }^{3}$ School of Chemical Sciences, North Maharashtra University, Jalgaon-425 001, India

${ }^{4}$ Department of Engineering Sciences, Rajarshi Shahu College Engineering, Tathawade, Pune-411 033, India

*Corresponding author: E-mail: s_dhondge@ @otmail.com

In this work, we report the determination of energy volume coefficient $\left(\mathrm{P}_{\mathrm{int}}=\left(\frac{\partial \mathrm{U}}{\partial \mathrm{V}}\right)_{\mathrm{T}}\right)$ also called as an internal pressure $\left(\mathrm{P}_{\mathrm{int}}\right)$ in the dilute concentration region for the basic carbohydrates i.e., glucose, fructose, sucrose, galactose and lactose in aqueous solutions at $288.15 \mathrm{~K}$ in the concentration range $0-0.05 \mathrm{~mol} \mathrm{~kg}^{-1}$. To obtain this one requires precise isothermal compressibility and expansivity data. We used earlier reported data of density $(\rho)$ and speed of sound $(\mathrm{u})$ obtained at $278.15,288.15$ and $298.15 \mathrm{~K}$; assuming specific heat $\left(\mathrm{C}_{\mathrm{P}}\right)$ is nearly the same in the studied concentration region. The internal pressure for solutions is found to increase with concentration of solute linearly and the increase depends upon the number of polar hydroxyl groups and conformational characteristics of the carbohydrate molecules. It is well known that apparent molar volumes of $\left(\phi_{\mathrm{v}}\right)$ of these compounds do not vary with concentration in dilute solution region (almost ideal solutions), while the conformational specificity is reflected only in limiting partial molar volumes because of solutesolvent interactions. We applied Gibson-Tait equation of state to internal pressure data and obtained limiting excess molar volumes $\left(\overline{\mathrm{V}}_{2}^{0 \mathrm{E}}\right)$ and found that values of excess molar volume of these compounds are highly negative $\left(-31 \times 10^{-6}\right.$ to $\left.-62 \times 10^{-6} \mathrm{~m}^{3} \mathrm{~mol}^{-1}\right)$ at 288.15 $\mathrm{K}$. These are large negative when compared with the molar volume data of solid carbohydrates. The differences are attributed to void volume and cage volume contribution to the total volume of solute molecule. It is invoked that when carbohydrates are dissolved in water, almost all free and void volumes are being used up due to dipole $(-\mathrm{OH})$ and water molecular interactions through hydrogen bonding and retaining water structural characteristics intact in solution phase.

Key Words: Isothermal compressibility, Internal pressure, Excess partial molar volume, Carbohydrates.

\section{INTRODUCTION}

The chemistry of polyhydroxy compounds (PHCs) is very important for life processes. One of the most important characteristics is their ability to interact with water by means of their hydrogen bonding potential ${ }^{1}$. Several properties of aqueous polyhydroxy compound solutions have been studied ${ }^{2}$. It has been discussed that the polyhydroxy compound solutions can be treated as semi-ideal and apparent derivation could be accounted for in terms of simple hydration equilibrium, each $-\mathrm{OH}$ group being associated with one water molecule ${ }^{3}$. Of all chemical species, the polyhydroxy compounds most closely resemble water in their properties. Stokes and Robinson using the concept of ideal solution suggested that the observed concentration dependence of the thermodynamic quantities is due to solute-water interaction in terms of hydration equilibria. It has been shown that for carbohydrates-water systems free energies, as a result of enthalpy-entropy compensation effects ${ }^{2,4}$ may be fairly insensitive to the hydration model chosen ${ }^{5}$. Franks et al. ${ }^{5}$ have developed specific hydration model for aqueous carbohydrate solutions using calorimetric and dielectric measurements. According to them the nature and extent of hydration is a function of relative compatibility of the solute conformation with the aqueous environment as well as by the intermolecular order through hydrogen bonding interaction. Warner and $\mathrm{Ann}^{6}$ has discussed the correlation between the stereochemistry of sugar and their hydration behaviour with reference to biological specificity and cryoprotective action. It has been noted that no reliable data of free energy changes are available in dilute concentration range; it may be because 
of complication due to mutarotation at lower temperature. However, the recent results of osmotic coefficient and excess free energy changes have shown the hydration number of 1012 , compatible with clathrate hydrate structure (class I) in solution phase. Franks ${ }^{1}$ has stressed the importance of specific heat data to find hydration details. However, the results are not conclusive because of the complications due to changes in the internal degrees of freedom of the solute molecule when it is removed from its crystalline environment ${ }^{7}$. Similar problems occur when one deals with volumetric properties of sugars. The limiting partial molar volume of solute $\left(\overline{\mathrm{V}}_{2}^{0}\right)$ is mainly a function of molecular weight. However, the concentration dependence of apparent molar volume is also nil or negligible showing the absence of solute-solute interaction ${ }^{8,9}$. The excess partial volume $\left(\overline{\mathrm{V}}_{2}^{\mathrm{E}}\right)$ data cannot be used with ease to draw meaningful information (for comparison with other solutes or conformers), as $\mathrm{V}_{2}{ }^{0}$ (molar volume) of sugars calculated from van der Waals radii or of solids as reference states do not corroborate.

It is known from the literature that the limiting excess partial molar volumes $\left(\overline{\mathrm{V}}_{2}^{0 \mathrm{E}}\right)$ of electrolytes can be obtained by application of Gibson-Tait equation of state which can further be analyzed in terms of electrostatic, void volume, cage volume and intrinsic volume components ${ }^{10-13}$. This treatment needs fine data of internal pressure which can be evaluated if isothermal compressibility, expansivity and specific heat data in limiting concentration range is available. In recent years, the fine data became available for dilute aqueous solutions and we were successful in obtaining reliable excess volumes for alcohols in aqueous solutions which can be accounted satisfactorily in terms of water-structure making effect and hydrophobic interaction ${ }^{14}$. We now extend this treatment to aqueous-carbohydrate solutions for which fine data of adiabatic compressibility and volume are available at 278.15, 288.15 and $298.15 \mathrm{~K}$ in dilute concentration range $\left(0-0.05 \mathrm{~mol} \mathrm{~kg}^{-1}\right)^{8}$. The methodology of obtaining isothermal compressibility, expansivity and internal pressure at various concentrations is described and finally the excess limiting volume evaluation using Gibson-Tait equation is presented. The details of all these and possible interpretation are described in this study.

Methodology to obtain isothermal compressibility $\left(\boldsymbol{\beta}_{\mathrm{T}}\right)$ and internal pressure data $\left(\mathbf{P}_{\text {int }}\right)$ : The isentropic compressibility $\left(\beta_{\mathrm{S}}\right)$ was calculated by using data of density $(\rho)$ and speed of sound $(\mathrm{u})$ reported earlier ${ }^{8}$ by using the eqn. 1 .

$$
\mathrm{k}_{\mathrm{S}}=\frac{1}{\mathrm{u}^{2} \rho}
$$

where, $\rho$ is density of solution and $u$ is speed of sound in solution. Our speed of sound data $(\mathrm{u})$ were obtained by phase comparison interferrometry ${ }^{8}$ having accuracy of \pm 0.02 to $0.03 \mathrm{~m} / \mathrm{s}$.

The coefficient of expansion $\left(\alpha_{P}\right)$ is determined at 288.15 $\mathrm{K}$ by variation of $\rho$ with varying temperature at $278.15,288.15$ and $298.15 \mathrm{~K}$ at specified molalities using the relation:

$$
\alpha_{P}=-\frac{1}{\rho}\left(\frac{\partial \rho}{\partial T}\right)_{P}
$$

The calculations of isothermal compressibility $\left(\mathrm{k}_{\mathrm{T}}\right)$ were made by using, $\mathrm{k}_{\mathrm{S}}, \alpha_{\mathrm{P}}$ and the specific heat at constant pressure $\left(\mathrm{C}_{\mathrm{p}}\right)$ data and using the equation:

$$
\mathrm{k}_{\mathrm{T}}-\mathrm{k}_{\mathrm{S}}=\delta=\frac{\alpha_{\mathrm{P}}^{2} \mathrm{~T}}{\alpha}=\frac{\alpha_{\mathrm{P}}^{2} \mathrm{~T}}{\mathrm{C}_{\mathrm{p}} \rho}
$$

$C_{P}$ values for the solution are assumed to be the same as that of the solvent (water). The values for $\mathrm{u}, \beta_{\mathrm{S}}, \beta_{\mathrm{T}}$ and $\mathrm{C}_{\mathrm{P}}$ for pure water were $1466.4 \mathrm{~m} \mathrm{~s}^{-1}, 46.5464 \times 10^{-11} \mathrm{~Pa}^{-1}, 46.7039 \times 10^{-11}$ $\mathrm{Pa}^{-1}$ and $0.99976 \mathrm{Cal} \mathrm{g}^{-1} \mathrm{~K}^{-1}$, respectively at $288.15 \mathrm{~K}$. The variation of $\delta$ is the main contributing factor in obtaining values which in turn depend upon the accuracy of expansivity coefficient $^{15}$. Our data of isothermal compressibility $\left(\beta_{\mathrm{T}}\right)$ having an accuracy of $\pm 0.01 \times 10^{-11} \mathrm{~Pa}^{-1}$ at $288.15 \mathrm{~K}$ for various aqueous solutions are depicted in Fig. 1.

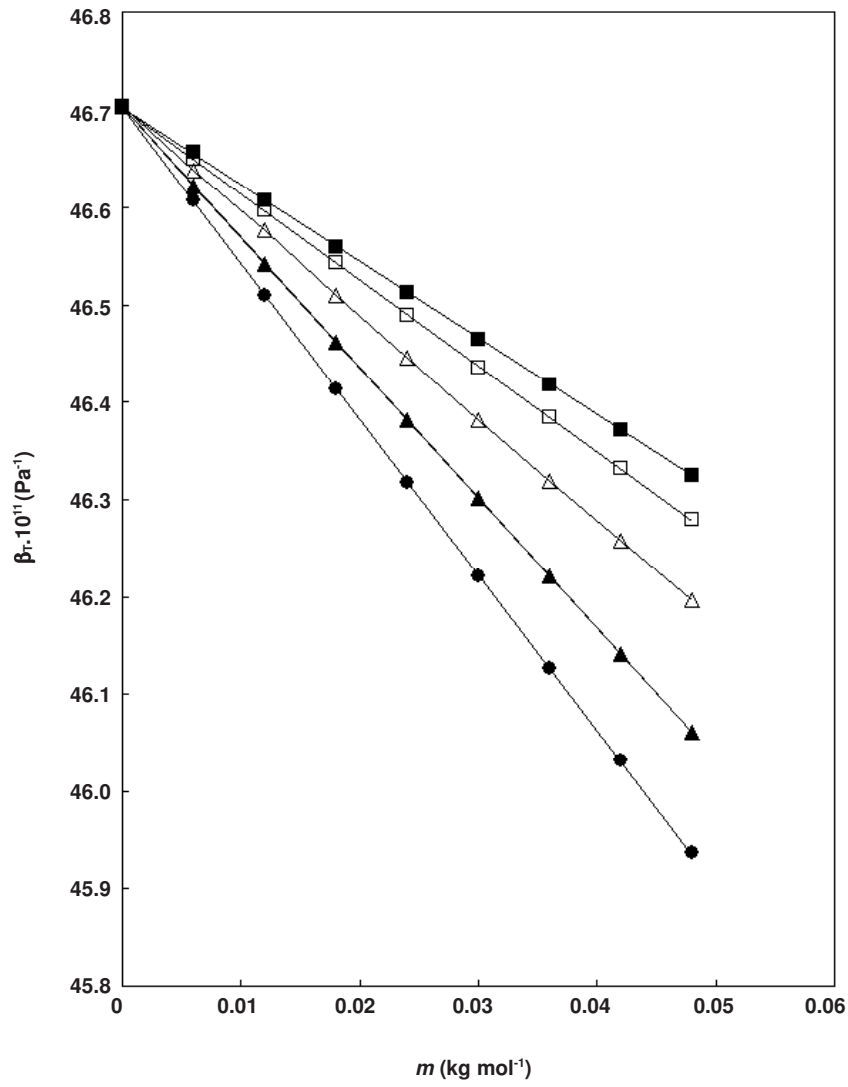

Fig. 1. Plot of isothermal compressibility $\left(\beta_{\mathrm{T}}\right)$ of aqueous solution of carbohydrates at $288.15 \mathrm{~K}: \square-\square$, glucose; $\square-\square$, fructose; $\triangle-\triangle$, galactose; $\boldsymbol{\Delta}-\mathbf{\Delta}$, sucrose; $\mathbf{-}-\boldsymbol{O}$, lactose

The energy volume coefficient (internal pressure) i.e., $\mathrm{P}_{\text {int }}$ values for aqueous solutions of carbohydrates at different concentrations were evaluated using the equation of state:

$$
\mathrm{P}_{\text {int }}=\left(\frac{\partial \mathrm{U}}{\partial \mathrm{V}}\right)_{\mathrm{T}}=\mathrm{T}\left(\frac{\partial \mathrm{S}}{\partial \mathrm{V}}\right)_{\mathrm{T}}-\mathrm{P}=\mathrm{T}\left(\frac{\partial \mathrm{P}}{\partial \mathrm{T}}\right)_{\mathrm{V}}-\mathrm{P}=\mathrm{T} \beta_{\mathrm{V}}-\mathrm{P}
$$

where, $\beta_{\mathrm{V}}$ is thermal pressure coefficient. Assuming P (1 atm $=101325 \mathrm{~Pa})$ is negligible and using $\left(\frac{\partial \mathrm{P}}{\partial \mathrm{T}}\right)_{\mathrm{V}}=\frac{\alpha_{\mathrm{p}}}{\mathrm{k}_{\mathrm{T}}}$, equation 4 becomes

$$
\mathrm{P}_{\text {int }}=\mathrm{P}\left(\frac{\partial \mathrm{P}}{\partial \mathrm{T}}\right)_{\mathrm{V}}=\mathrm{T} \beta_{\mathrm{V}}=\frac{\alpha_{\mathrm{p}} \mathrm{T}}{\mathrm{k}_{\mathrm{T}}}
$$

The variation of internal pressure $\left(\mathrm{P}_{\text {int }}\right)$ as a function of molality (m) of carbohydrates at $288.15 \mathrm{~K}$ is shown in Fig. 2. 


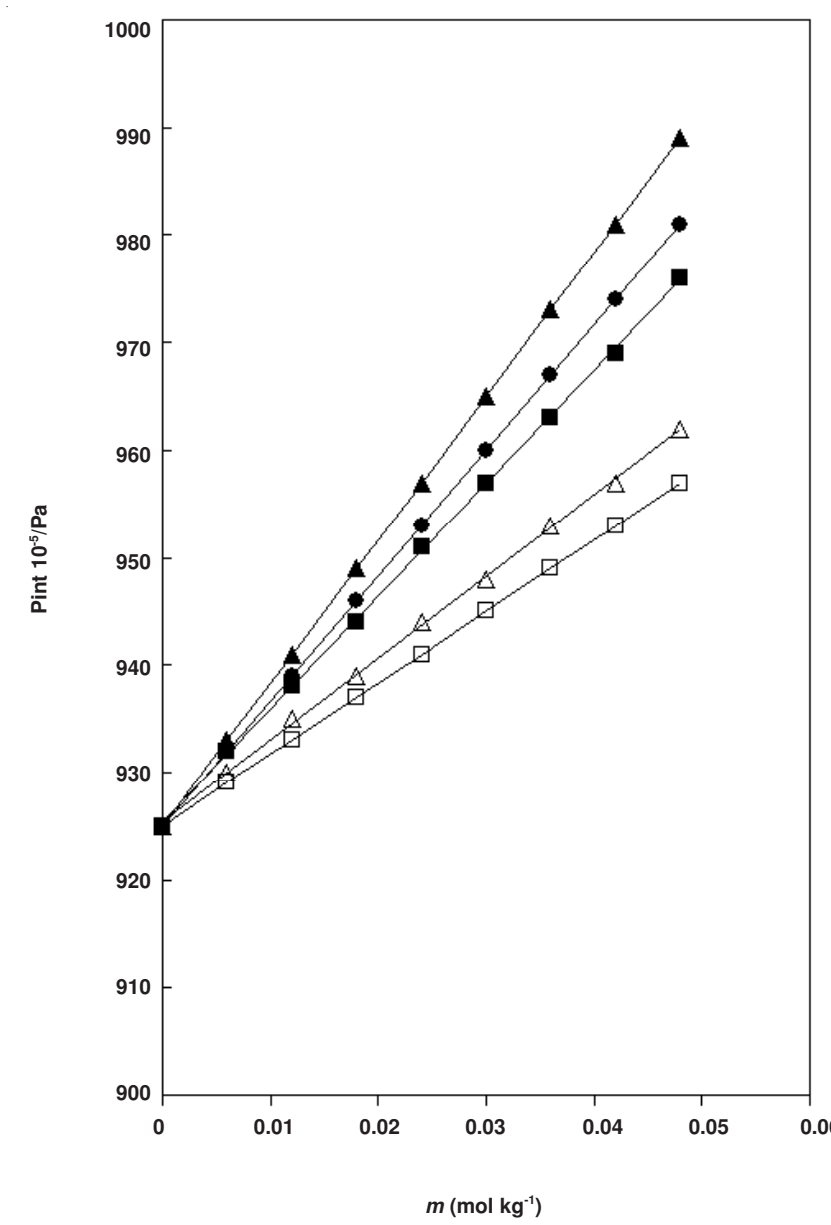

Fig. 2. Plot of Internal pressure $\left(\mathrm{P}_{\text {int }}\right)$ of aqueous solution of carbohydrates at $288.15 \mathrm{~K}: \square-\square$, glucose; $\square-\square$, fructose; $\triangle-\triangle$, galactose; sucrose; - lactose

The details about Gibson-Tait equation are given elsewhere ${ }^{11}$. The useful equation is:

$$
\overline{\mathrm{V}}_{2}^{(\rho)}-\mathrm{M}_{2} \mathrm{v}_{2}=-\frac{434.3 \mathrm{C}}{\mathrm{v}_{\mathrm{o}}\left(\mathrm{B}+\mathrm{P}_{\text {int }}+\mathrm{P}\right)} \cdot \frac{\partial\left(\mathrm{B}+\mathrm{P}_{\text {int }}\right)}{\partial \mathrm{m}}
$$

where $\mathrm{C}$ and $\mathrm{B}$ are positive constants. The $\frac{\mathrm{C}}{\mathrm{v}_{\mathrm{o}}}\left(\mathrm{v}_{\mathrm{o}}\right.$ being the apparent specific volume of solvent) term having a value of 0.3150 while the B is $2996 \times 10^{5} \mathrm{~Pa}$ at $298.15 \mathrm{~K}$. The $v_{2}$ is specific volume of pure solute (as a liquid). We can call $\mathrm{P}_{\text {int }}$ as the effective internal pressure created in solution due to dipole-dipole ( $\mathrm{H}$ bonding) and hydrophobic interaction between the solute molecules. The equation shows that the magnitude of the partial molar volume of solute is governed by two factors. The term $\frac{\partial\left(\mathrm{B}+\mathrm{P}_{\mathrm{int}}\right)}{\partial \mathrm{m}}$ is the rate of change of total internal pressure with concentration and is a function of both solvent and solute. The term $\frac{434.3 \mathrm{C}}{\mathrm{v}_{\mathrm{o}}\left(\mathrm{B}+\mathrm{P}_{\text {int }}+\mathrm{P}\right)}$ is related to the compressibility of the solvent at the pressure $\left(\mathrm{P}_{\text {int }}+\mathrm{P}\right)$ and is independent of solute. $P_{\text {int }}$ is considered to have constant characteristics for a given system at constant composition and temperature.
Gibson ${ }^{10}$ derived the equation:

$$
\overline{\mathrm{V}}_{2}^{0}-\mathrm{V}_{2}^{0}=\frac{-1000}{\left(\mathrm{~B}+\mathrm{P}_{\text {int }}+\mathrm{P}\right)} \cdot \frac{\partial\left(\mathrm{B}+\mathrm{P}_{\mathrm{int}}\right)}{\partial \mathrm{m}}
$$

where $\mathrm{m}$ is the molality of solution and $\mathrm{V}_{2}{ }^{0}$ is taken to be the hypothetical molar volume of the pure solute in the liquid state at the temperature and pressure of the experiment. The volume change $\overline{\mathrm{V}}_{2}^{0}-\mathrm{V}_{2}^{0}$ is therefore the change in the volume on mixing this hypothetical pure liquid solute and the solvent. To obtain the value of excess partial molar volume $\left(\bar{V}_{2}^{0}-V_{2}^{0}\right)$ at infinite dilution, we must take the limiting case of eqn. 7 . The term $\frac{1000}{v_{0}\left(B+P_{i n t}+P\right)}$ represents the compressibility of solvent at an external pressure $\left(\mathrm{P}_{\mathrm{int}}+\mathrm{P}\right)$. At infinite dilution of the solute this can be replaced by the compressibility of pure water $\mathrm{k}_{\mathrm{T}}$ at $1 \mathrm{~atm}\left(46.70 \times 10^{-11} \mathrm{~Pa}^{-1}\right.$ at $\left.288.15 \mathrm{~K}\right)$. eqn. 7 , then reduces to

$$
\bar{V}_{2}^{0}-V_{2}^{0}=\frac{k_{T}}{\rho_{0}} \lim _{m \rightarrow 0} \frac{d}{d m}\left(B+P_{\text {int }}\right)
$$

The density data of pure solids at $293.15 \mathrm{~K}$ are used to estimate molar volume of solids ${ }^{16}$. We assume that there will be no appreciable error for $\mathrm{V}_{2}{ }^{0}$ at $15^{\circ} \mathrm{C}$ due to this. These values are used to estimate excess partial molar volume at infinite dilution $\overline{\mathrm{V}}_{2}^{0 \mathrm{E}}\left(=\overline{\mathrm{V}}_{2}^{0}-\mathrm{V}_{2}^{0}\right)$ based on solid as standard state.

\section{RESULTS AND DISCUSSION}

Fig. 1 reveals that $\beta_{\mathrm{T}}$ decreases with concentration of solute in solution $(\mathrm{m})$ in all studied systems. The relative decrease is lowest for fructose while it is highest for lactose. These small differences can be attributed to conformational differences in carbohydrate structures. It may be due to the fact that equatorial-OH group is hydrated more than the axial one. The same observation was made by Kaulgud and Dhondge ${ }^{8}$ and Franks et al. ${ }^{9}$.

It is observed from Fig. 2 that the internal pressure parameter $\left(\mathrm{P}_{\mathrm{int}}\right)$ increases linearly in all the systems. The $\frac{\partial \mathrm{P}_{\text {int }}}{\partial \mathrm{m}}$ value is highest for sucrose while it is lowest for glucose. The number of -OH groups (in sucrose it is 8 , while in glucose it is 4) decides this rise because of dipole-dipole hydrogen bonding interaction between - $\mathrm{OH}$ and water molecule interaction.

There is no appreciable difference in the densities of solids studied in this work and so excess volumes do not show a trend when solid state is taken as a standard state (Table-1). Lactose shows the highest volume loss. We observed earlier ${ }^{8}$ that the limiting apparent molar compressibility $\left(\phi_{\mathrm{KS}}^{0}\right)$ of lactose is highly negative meaning strong dipole-solvent interaction similar to that of electrostriction. Lactose is a combination of glucose and galactose (both are in pyranose form). Therefore the pyranose and furanose form (sucrose) do cause solute-solvent interaction but the extent of hydration is more for pyranose form. The magnitude of $\bar{V}_{2}^{0 E}$ for 


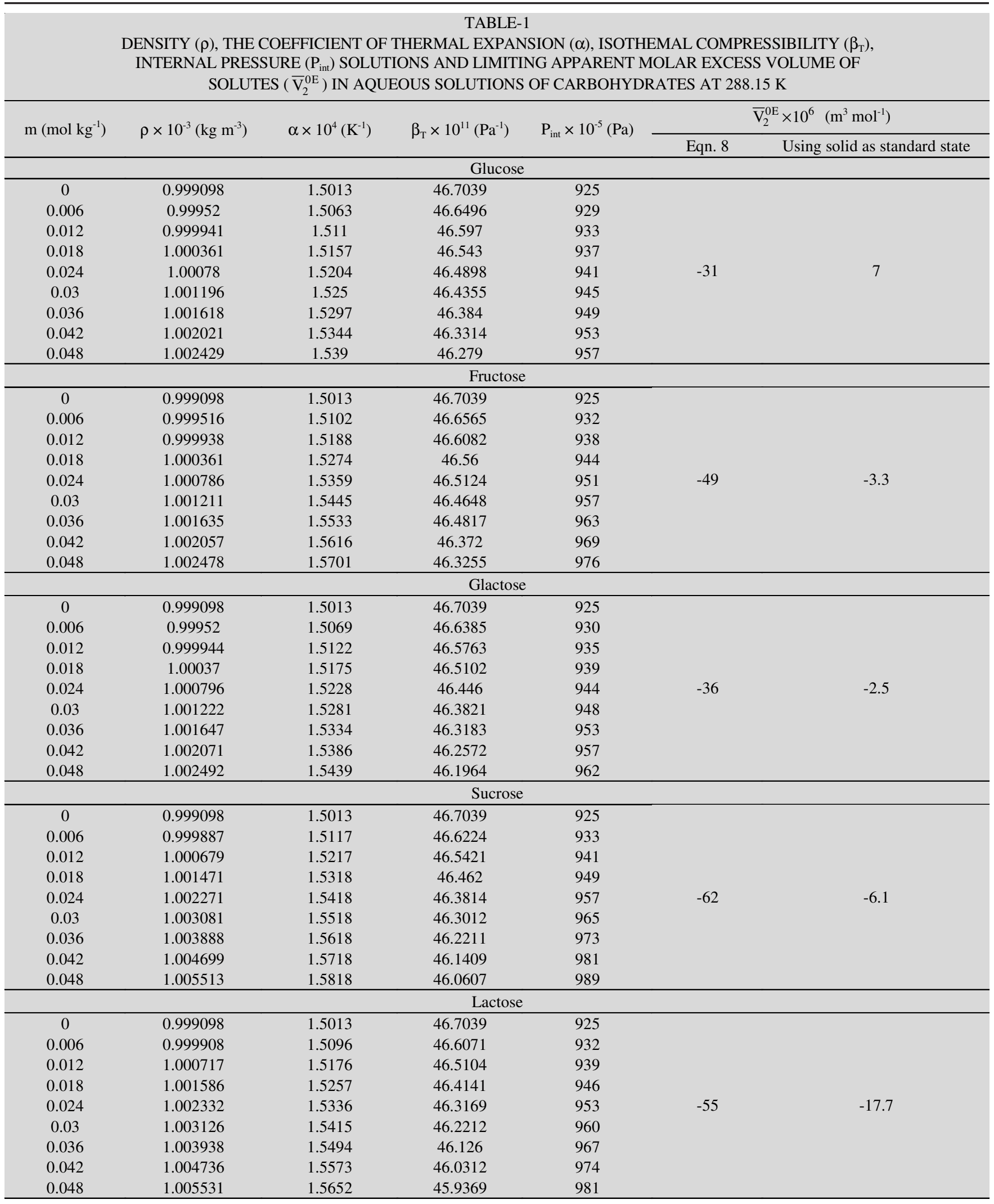

monosaccharide is similar to that of alcohols; however the details of interactions are different. In alcohols the volume loss is due to hydrophobic interaction ${ }^{17}$ (dissolution with economy of space), while for monosaccharides it is due to dipole-dipole interaction.

When this excess volume based on solid as a standard state is compared with those obtained with Gibson-Tait equation, we find that in the latter case, these are highly negative $\left(-31\right.$ to $\left.-62 \mathrm{~cm}^{3} \mathrm{~mol}^{-1}\right)$. It is now certain, that solid as standard state is inadequate to account for interaction. Edward ${ }^{18}$ has tried to understand molecular volumes of various molecules. He estimated van der Waals volumes and divided into atomic increment as well as calculated free volume due to empty space. At $0 \mathrm{~K}$, a crystal made of closed-packed spheres 
has only $74 \%$ of its total volume occupied by the spheres. In view of this, our excess volume for carbohydrates indicate large negative volume ranging from -31 to $-62 \mathrm{~cm}^{3} \mathrm{~mol}^{-1}$. Since these calculations are based on best equation of state, it is concluded that so much free space is available for these molecules. Thus, the empty volume associated with these molecules in aqueous solutions is roughly the same as the empty volume associated with carbohydrate molecules in the solid or liquid state $\left(\frac{\overline{\mathrm{V}}_{\mathrm{M}}}{\mathrm{V}_{\mathrm{W}}}=1.38\right)$. We found no evidence of solute-solute association for these solutes; hence it is clear that the empty volume is all available for $\mathrm{H}$-bonding (dipoledipole) interaction with water molecules. The detailed numerical agreement of course would depend on the stereochemical/ conformational specificity of the molecules. The empty volume will be reduced by hydrogen bonding between solute and solvent water, which will bring them closer together yielding the negative excess molar volumes.

Following the treatment advanced for ionic solution by Millero $^{13}$, the solute molecules at infinite dilution are far away from each other, each interacting with the surrounding water molecules in its own unique way. The $\overline{\mathrm{V}}_{2}$ of glucose can be represented by four major components:

$$
\overline{\mathrm{V}}_{2}^{0}=\mathrm{V}_{2 \text { cryst }}^{0}+\overline{\mathrm{V}}_{\text {elect }}^{0}+\overline{\mathrm{V}}_{\text {disord(viod) }}^{0}+\overline{\mathrm{V}}_{\text {cage }}^{0}
$$

Since there are no ions, $\overline{\mathrm{V}}_{\text {elect }}^{0}$ will be zero but will be replaced by $-\mathrm{H}$ bonding and dipole-dipole interaction contribution. Therefore, the excess partial molar volume will correspond to

$$
\overline{\mathrm{V}}_{2}^{0}-\mathrm{V}_{\text {2cryst }}^{0}=\mathrm{V}_{\text {dipole interaction }}^{0}+\overline{\mathrm{V}}_{\text {disord(viod) }}^{0}+\overline{\mathrm{V}}_{\text {cage }}^{0}
$$

We obtained directly by application of Gibson-Tait equation which corresponds to the effects due to sum of H-bonding and $\overline{\mathrm{V}}_{\text {cage }}^{0}$ (water structural effects) subtly. The values obtained are shown in Table-1. Therefore, it is concluded that the availability of hydroxyl grouping, the number of intermolecular hydrogen bonds per molecule in the crystal and free space available determine the thermodynamic properties of aqueouscarbohydrate solutions. The remarkable loss of apparent volume observed demonstrates the resemblance between water molecules and $-\mathrm{OH}$ groups in carbohydrate. Polyhydroxy compounds are well known for their ability to protect native proteins and nucleotides against the denaturing effects of dehydration ${ }^{19}$. Polyhydroxy compounds are also employed by living organism as protestants against physiological water stress, whether due to low temperature, drought or solubility ${ }^{20}$.

\section{Conclusion}

The interactions between polyhydroxy compounds and water, like those between water molecules, are governed by hydrogen bonding. The large negative excess volumes reported, signify large free volume associated with these molecules. The detailed manifestation in thermodynamic properties seems to depend on solute-solvent interactions and are very sensitive to spacing and orientation of the $-\mathrm{OH}$ groups on the solute molecule. Where, different conformers can coexist in solution, the aqueous solvent acts so as to favour the conformers with largest number of equatorial -OH groups because of their special compatibility with water.

\section{REFERENCES}

1. F. Franks, Cryobiology, 20, 335 (1983).

2. F. Franks and A. Water. In ed.: F. Franks, Comprehensive Treatise, Plenum Press, New York, Vol. 4 (1973).

3. R.H. Stokes and R.A. Robinson, J. Phys. Chem., 70, 2126 (1966).

4. J.J. Kozark, W.S Kauzman and W.S. Knight, J. Phys. Chem., 48, 675 (1568).

5. F. Franks, D.S. Reid and A. Sugget, J. Soln. Chem., 2, 99 (1972).

6. D.T. Warner and N.Y. Ann, Acad. Sci., 125, 605 (1965).

7. R. Kolhapurkar, Ph.D Thesis. Shivaji University, Kolahapur, India (2006).

8. M.V. Kaulgud and S.S. Dhondge, Indian J. Chem., 27A, 6 (1988).

9. F. Franks, J.R. Ravenhill and D.S. Reid, J. Soln. Chem., 1, 3 (1971).

10. R.E. Gibson, J. Am. Chem. Soc., 57, 284 (1935).

11. H.S. Harned and B.B. Owen, The Physical Chemistry of Electrolytic Solutions Reinhold Publishing Corporation, New York (1959).

12. P. Mukherjee, J. Phys. Chem., 65, 744 (1961).

13. F.J. Millereoin, In ed.: R.A. Horne, Water and Aqueous Solutions, Wiley Intersicence NY (1972).

14. S.S. Dhondge, P. Patil and K.J. Patil, Asian J. Chem., 24, 2107 (2012).

15. J.G. Matheson and B.E. Conwey, J. Chem. Soc. Faradays Trans., 70, 752 (1974).

16. CRC Handbook Physics and Chemistry.

17. A. Ben-Naim, Hydrophobic Interactions, Plenum Press, New York and London (1980).

18. J.T. Edward, J. Chem. Educ., 47, 261 (1970).

19. J.F. Brondts, J. Fu and J.H. Nordin, In eds.: G.E.W. Wolstenholme and M.O. Conner, In Frozen Cell, Ciba Foundation Symp (1970).

20. F. Franks, In eds.: F. Franks and S.F. Mathias, In Biophysics of Water, Wiley, Chichester (1982). 